\title{
CASE STUDY ON THE USE OF X-RAY INSPECTION SYSTEM FOR SAFE SCREENING OF PASSENGER VEHICLES AND VANS WITH MINIMAL EFFECT ON THE TRAFFIC FLOW
}

\author{
Fulger Ciupagea ${ }^{1}$, Constantin Sima², Doru Petru Munteanu², \\ Anton Iuliu Demetriu Coroianu², Gabriela Rosca Fartat ${ }^{1^{*}}$
}

\author{
${ }^{1}$ Ministry of Health, Public Health Directorate-Radiation Hygiene Laboratory, Bucharest, Romania
} ${ }^{2} \mathrm{SC}$ MB Telecom Ltd, Bucharest, Romania

\begin{abstract}
According to the current ICRP Recommendations, the principles of justification, optimization, and dose limitation for the planned exposure situations are directly applicable to the use of ionizing radiation in the security screening. The use of different X-ray inspection systems is carried out in some States and prohibited in others, and there are no published regulatory decisions on the formal justification of this type of practice. The decision for the use of $X$-rays involving human imaging for the security screening shall be justified by the government. The aim of this paper is to present the quantitative assessment of the radiation detriments and the expected benefits of a designed screening system, as well as the analysis of the measurements performed to demonstrate the respect of the dose constraints for the members of the public and the conformity with the IAEA recommendations and the applicable standards.
\end{abstract}

Key words: Detriment, justification, non-medical human imaging, planned exposure situations, security screening

DOI: $10.21175 / \operatorname{RadProc} .2017 .15$

\section{INTRODUCTION}

The significant increase of interest in security concerns worldwide led to the use of ionizing radiation in designing of the security screening systems. The use of ionizing radiation for the security purposes imaging techniques causes the increase of the deliberate exposure of individuals. According to the Recommendations of the International Commission on Radiological Protection [ICRP], the use of ionizing radiation to screen individuals for security purposes is an exceptional circumstance which requires careful justification since it is unacceptable to presume that the exposure is generically justified [1]. The paper describes how the radiation protection principles of the ICRP are applied within the context of the presented security screening system, following the ICRP advice on the application of the specific recommendations [2].

The radiation safety assessment is performed by the designer, according to the IAEA Safety Standards (GSG-5), in order to demonstrate to the regulatory bodies that this practice is justified [3].

\section{SYSTEM DESCRIPTION}

TudorScan OCV is a fixed portal X-ray inspection system used for scanning occupied cars and vans. The system is designed to detect threats (weapons, bombs, explosives) and/or illegal traffic of goods by a nonintrusive inspection. The system provides a radiographic image by using a collimated X-ray beam, while the vehicle is driven through the scanning portal with limited speed by the driver. At the entrance to portal, the presence sensor triggers the radiation beam, so that the beam is turned on only while the vehicle passes through the portal. Traffic before and after the scanning is managed by using the barriers and traffic lights interconnected with the portal (Figure 1). The workers use specific integrated software for controlling the system and for image analysis.

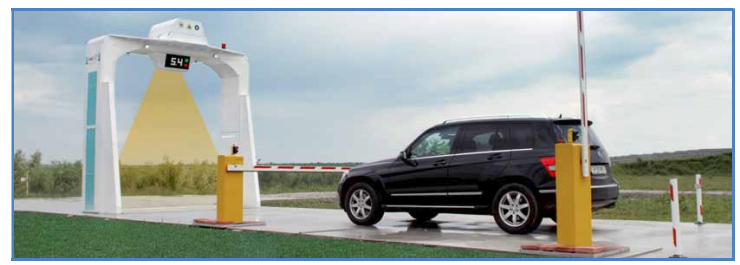

Figure 1. TudorScan OCV

The mechanical structure consists of three modular housings connected in an upside-down U shape and detectors on the ground (Figure 2):
- Vertical Housing 1 (VH1)
- Vertical Housing 2 (VH2)
- Horizontal Housing ( $\mathrm{HH})$
- Detectors 


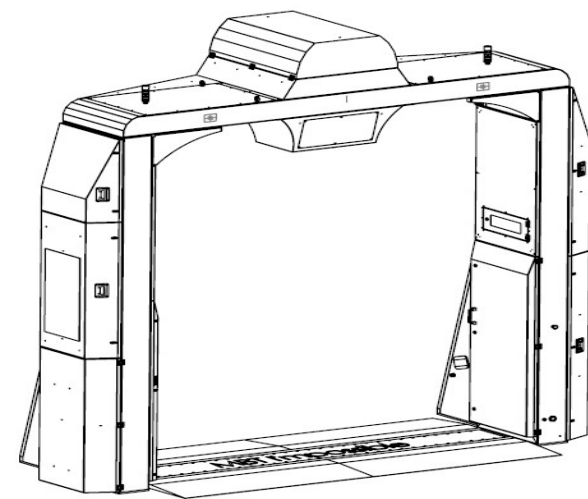

Figure 2. Portal structure

The portal is the mechanical support for the automation panel, the controller of the X-ray generator, the License Plate Recognition (LPR), surveillance camera, the vehicle detection sensors, the emergency stop buttons (ESD), safety key switch. The system also contains a cooling unit (chiller) and cooling distribution system, signaling lamps and light projectors. The detector system (D) consists of detector modules access ramps.

The system is controlled from a command center (Figure 3) placed outside the exclusion area, where an operator also analyses the radiographic image of the inspected vehicle.

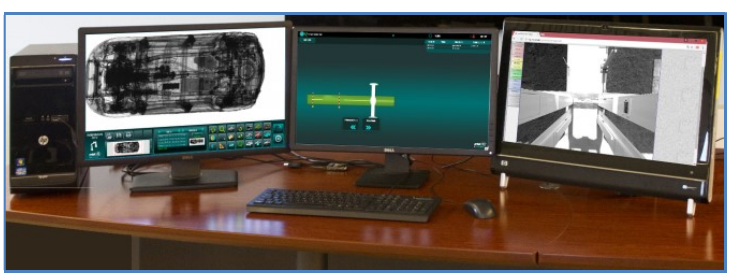

Figure 3. Command center

The data acquired from the detectors is sent to the command center by wired or wireless communication, where the radiographic image is displayed in real time. The entire exclusion area is surveilled by a video camera and any intrusion during the scanning process is signaled by the system called the Automatic Protection of the Exclusion Area (APEA). The system is equipped with infrared sensors that automatically stop the beam when an intruder is detected.

\section{JUSTIFICATION}

\subsection{Benefits}

Considering the fact that many times the vehicles were used to transport explosive materials, weapons and ammunition in the areas of the planned attacks, it is clear that the use of the vehicle occupant scanning would increase the effectiveness of security measures.

There are obvious benefits of the practice of X-ray inspection system used for scanning the occupied cars and vans, for both society and individuals, which include the following:

(a) Social benefit - security checks using modern technologies increase the safety of citizens and contribute to ensuring a high level of security for society as a whole. Depending on the objective pursued, a failure to use X-ray scanners for vehicles can cost much more than the loss of human lives and the damage (direct) and indirect losses to society (decreased confidence in the authorities, induction of panic and terror). In addition, the presence of such inspection points is a serious deterrent for criminals and has significant benefits for the society.

(b) Individual benefits - increased individual confidence. People are clearly influenced by security, as it was seen in relation to a significant increase in the number of terrorist attacks.

(c) National and international economic benefits attacks have led to significant financial and economic losses.

\subsection{Detriments}

The effective dose calculated by using the reference model [4] was estimated at $0.05 \mu \mathrm{Sv}$ per scan performed by the system TudorScan OCV. The reference model was positioned on the driver's place within a medium size car. The dose for each organ was estimated taking into account the exposure time (given by the scanning speed and the beam width) and the dose rate.

The total dose to an individual in a year will, of course, depend on the number of times the individual was subjected to such an exposure. If, for example, an individual is subjected to 1460 such examinations in a year, the total effective dose would be of the order of 73 $\mu \mathrm{Sv}$. According to the linear model [1], the risk of the occurrence of stochastic effects can be determined for a scan, and for a person that is scanned 4 times a day, 365 days according to the Table 1 .

Table 1. Estimation of risks of stochastic effects

\begin{tabular}{|c|c|c|}
\hline $\begin{array}{c}\text { Number of } \\
\text { exposures }\end{array}$ & Effective dose & $\begin{array}{c}\text { The probability } \\
\text { of a stochastic } \\
\text { effect }\end{array}$ \\
\hline 1 & $0.05 \mu \mathrm{Sv}$ & $3.0 \times 10^{-9}$ \\
\hline $\begin{array}{c}4 \text { exposures/day, } \\
365 \text { days/year }\end{array}$ & $73 \mu \mathrm{Sv}$ & $4.4 \times 10^{-6}$ \\
\hline
\end{tabular}

The values shown in Table 1 indicate that the risk of fatal cancer induced by radiation is negligible compared to the risks of death from other causes (Figure 4).

However, the risk of death from stochastic effect has to be compared not only with other causes but also with the risk of death from terrorist attacks. For example, in Turkey more than 400 people died in 2015 from terrorist attacks [9]. Relating to a population of 80 million, the overall probability of death from terrorist attacks is $5 \times 10^{-6}$. This value is significantly higher than the risk of stochastic effect of $3.0 \times 10^{-9}$ (one scan/year) and comparable with $4.4 \times 10^{-6}$ (4 scans/day, 365 days/year). Obviously, the number of persons scanned daily is smaller compared to the 
entire population of a country, leading to a small probability of stochastic effect.

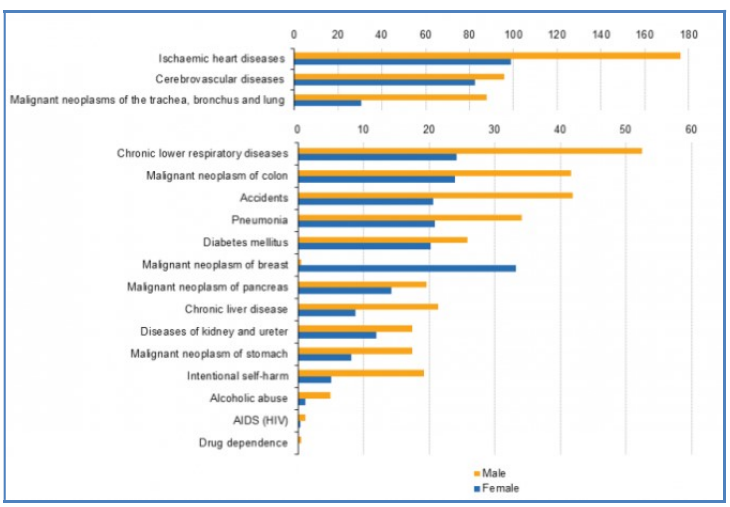

Figure 4. Eurostat death rates for 100.00o inhabitants in EU 2013

\subsection{Evaluation}

The dose from a single examination to an individual is very low and is substantially lower than an individual would receive from cosmic rays even during a one-hour flight, of $3 \mu \mathrm{Sv} / \mathrm{h}$. Even if individuals are the subjects to many examinations in a year, the total effective dose would still be very low. On the other hand, the consequences of a failure to detect a hidden weapon could be considerable. In order to make a clear picture of the threatening environment to support decision-making, the inputs of security and intelligence organizations are needed. The process of comparing the beneficial and detrimental factors is complex, involves different authorities and is supported by the designer assessment and other independent evaluations.

Using a very low exposure, the OCV TudorScan system provides high resolution radiographic images of the vehicles scanned with a high level of details, enabling the operator to detect potential threats to human security and strategic objectives (guns, bombs, hazardous materials) through the use of advanced software tools. The sub-millimeter resolution and material discrimination capability allow the user to identify the small amounts of explosives, tens of grams hidden in the car inspected (e.g. Figure 5).

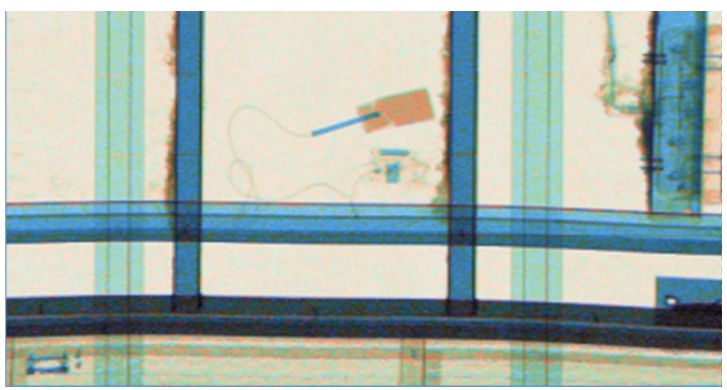

Figure 5. Explosive (100 grams) hidden in the inspected car

For example, India has about 1.3 billion people. Assuming that, in theory, all of them are scanned once in a year with OCV system (or similar), then, extrapolating the value from Table 1 , the number of persons that are likely to be affected by the stochastic effect is about 4 . In 2016, there were about 60 people killed by terrorist attacks in India [8]. Assuming that at least $20 \%$ of the lives could be saved by using checkpoints of the scanning systems, we may compare at a theoretical level the detriment of 4 persons affected by X-ray radiation stochastic effects with 12 persons saved.

\subsection{Decision}

The process of comparing the beneficial and detrimental factors is complex, involves different authorities and is supported by the designer assessment and other independent evaluation. The decision to use X-rays involving human imaging for security screening is made by the government.

If the decision that the use of the X-ray inspection system for the safe screening of passenger vehicles and vans is justified, the framework for protection as a planned exposure situation must be applied, including the optimization of protection and the appropriate provisions for the regulatory control.

\section{OPTIMIZATION}

\subsection{Optimization of occupational exposures}

Occupational exposure may be received by operators, technicians doing the installation, service and maintenance, surveys and calibration, and other appropriate activities. The TudorScan OCV system provides an adequate shielding and distance from the source. Safety and radiation protection instructions for the workers are issued in the Installation and User's Manual.

\subsection{Optimization of screened individuals and public exposures}

Considering the specific scan vehicles occupied by the driver and possibly by other passengers, OCV TudorScan scanner manufacturer primary aim is to minimize the radiation dose delivered to the occupants during the equipment lifecycle-design, engineering, production, use and service.

OCV TudorScan scanner manufacturer has taken the concrete steps to optimize radiation protection:

- Collimation of the beam: the beam of X-radiation is collimated to the minimum necessary to cover the line of detectors; beam width at the detectors is few $\mathrm{mm}$, so that the dose of the beam was minimized directly (through reduced exposure time) and radiation dose scattered (through small surface scattering);

- The choice of the radiation generator: to minimize the radiation received by the occupants, the system is designed with a conventional X-ray generator;

- Additional shielding X-ray generator: the X-ray generator has an additional screen that leads the leakage radiation down to a negligible level;

- Automatic detection of the vehicle scanned: Scan Portal is equipped with a vehicle detection sensor, so that the $\mathrm{X}$ radiation is emitted only when the scan process is conducted; 
- The shutter: the X-ray beam is emitted by driving a lead shutter that minimizes exposure time; the electronic control of the generator produces an unstable beam in the first few seconds, so this transitional period cannot be used for scanning; on the stabilization of the beam, the shutter is closed, thereby reducing the radiation dose to the operators and members of the public;

- Additional filtration: the X-ray generator has an inherent filter from $\mathrm{Fe} / \mathrm{Ni} / \mathrm{Co}$ alloy; in order to reduce the low energy radiation that contributes to the dose received by the people scanned without significant contribution to the radiographic image quality, an additional filtration is used; the strengthened beam reduces the dose received by the persons in the inspected vehicle;

- Automatic validation of the vehicle speed: when the driver of the vehicle passing through the portal scan reduces the speed below the minimum acceptable value of $5 \mathrm{~km} / \mathrm{h}$, the system automatically stops the beam of radiation, protecting the driver and the occupants from receiving a higher dose generated by slowdown or stop for various reasons during the scanning;

- Commissioning and periodic maintenance: the manufacturer of the scanning system provides the verification of key parameters related to the radiation protection and safety.

\section{DosE LIMITS}

The use of security screening OCV TudorScan system, under the appropriately optimized radiation control program for planned exposure situations, respects the dose limits recommended by ICRP for the occupational and public exposure during the expected activities [1].

\section{TESTS}

\subsection{Tests objectives}

The objective of the tests performed by the Public Health Directorate-Radiation Hygiene Laboratory was to measure the ambient dose equivalent $\mathrm{H}^{*}(10)$ and to observe the respect of the dose limits for the public during the operation of the security screening system.

\subsection{Instrumentation, test methodology and} environment

The ambient dose equivalent measurements were performed in the points placed at the limit of the controlled area, defined by the manufacturer (10m x 10m) (Fig. 4), in the most conservative operation conditions:

- maximum X-ray generator operating parameters:

$\mathrm{U}=300 \mathrm{kV}, \mathrm{I}=0.5 \mathrm{~mA}$;

- maximum duration of the scanning process, corresponding to the lowest acceptable speed;

- minimum accessible distance from the scanner.

The system provided for the ambient dose equivalent measurements was an engineering unit built by the SC MB Telecom Ltd, Bucharest, Romania.
The engineering team used the components from their inventory and configured it to be at the same version level specified in "Technical Specification - TudorScan OCV," [5] and functionally equivalent to the system that could be installed to the customer premises, according to the Installation and User Manual [6].

The radiation instrument used to conduct the area monitoring was a RadEye G20-ER1o X-Ray survey meter (energy range $17 \mathrm{keV}-3 \mathrm{MeV}$ ) calibrated.

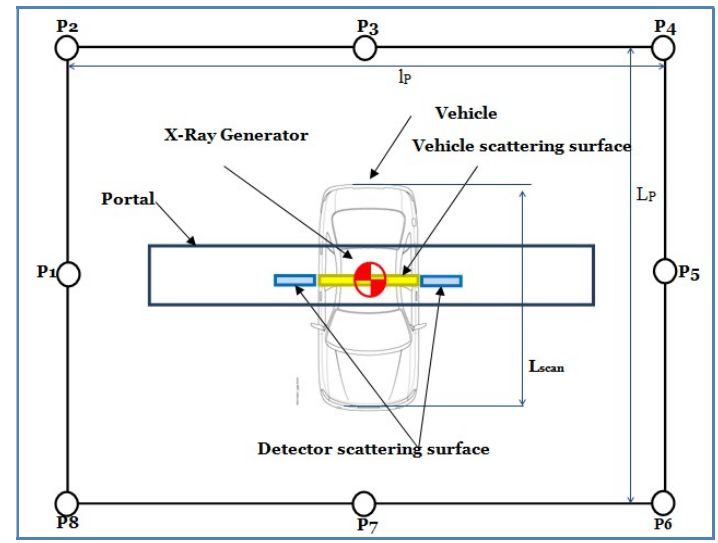

Figure 5. Area monitoring points

\subsection{Results}

The maximum and mean values measured of the ambient dose equivalent rates are presented in Table 2.

Table 2. Measured values of the ambient dose equivalent rate

\begin{tabular}{|c|c|}
\hline Point & $\begin{array}{c}\text { Measured value }(\boldsymbol{\mu S v} / \mathbf{h}) \\
\text { peak/mean during the scan }\end{array}$ \\
\hline 1 & $0.71 / 0.38$ \\
\hline 2 & $0.17 / 0.11$ \\
\hline 3 & $0.75 / 0.43$ \\
\hline 4 & $0.32 / 0.16$ \\
\hline 5 & $0.41 / 0.22$ \\
\hline 6 & $0.73 / 0.36$ \\
\hline 7 & $1.38 / 0.52$ \\
\hline 8 & $0.68 / 0.32$ \\
\hline
\end{tabular}

The peak value was the maximum dose rate recorded during a typical scan of a medium size car. The time window for the measurement was about 2 seconds (for a vehicle speed of $10 \mathrm{~km} / \mathrm{h}$ ). The X-ray generator is turned off between consecutive scans.

Typically, for a throughput of 400 vehicles/h, the dose for the operator is less than $0.5 \mu \mathrm{Sv}$ in one hour, $20 \mu \mathrm{Sv} /$ weak, $1 \mathrm{mSv} /$ year.

One may observe that these values are considered for the radiation safety of the operators and bystanders as they could be exposed to these doses $8 \mathrm{~h}$ per working day, and not for the scanned persons.

For the evaluation of the dose/scan for the vehicle occupant, the dosimeter was placed within a typical car. The average value (over 10 passes) was about $0.04 \mu \mathrm{Sv}$. 


\section{CONCLUSIONS}

The X-ray inspection system presented in this paper may be used within a planned exposure situation generating a low dose according to ALARA principle. It generates a high quality sub-millimeter resolution radiographic image that helps authorities detect threats like weapons, bombs, ammunition. The net benefits for the society are obvious, since detecting the threats in time might save many human lives. On the other hand, the justification of using TudorScan OCV for the occupied vehicle scanning has to consider all the radiation safety measures taken by the manufacturer early in the design phase -X-ray generator shielding, beam shutter usage, beam collimation, radiation filtration, vehicle speed detection, and low X-ray generator current. The system delivers extremely low doses to the driver and passengers of the inspected vehicle. Nevertheless, these measures are providing a good protection for the system operator and bystanders.

According to [7] the scanner classifies in Category 1 General-use systems, and Class A - full body scanners with an individual dose less than $250 \mathrm{nSv} / \mathrm{scan}$. The dose per year received by an individual scanned with OCV, even if he/she is scanned frequently (4 scans/day), is about $73 \mu \mathrm{Sv} /$ year which is below the limit of $250 \mu \mathrm{Sv} /$ year for an exposure situation with a single source of radiation.

However, if the X-ray scanning of the occupied vehicle practice is not authorized, the system can be used by pulling the inspected car without driver by means of a tug unit remotely controlled from outside the exclusion area.

\section{REFERENCES}

1. The 2007 Recommendations of the International Commission on Radiological Protection, 1st ed., ICRP, Ottawa, Canada, 2007.
Retrieved from:

http://www.icrp.org/docs/ICRP Publication 103-

Annals of the ICRP 37(2-4)-Free extract.pdf

Retrieved on: Jan. 15, 2017

2. D. A. Cool, E. Lazo, P. Tattersall, G. Simeonov, S. Niu, "Radiological Protection in Security Screening," Ann. ICRP, vol. 43, no. 2, 2014.

DOI: $10.1177 / 0146645313517031$

3. Justification of Practices, Including Non-Medical Human Imaging, 1st ed., IAEA, Vienna, Austria, 2014.

Retrieved from:

http://www-

pub.iaea.org/MTCD/publications/PDF/Pub1650web23654722.pdf

Retrieved on: Jan. 14, 2017

4. Basic Anatomical and Physiological Data for Use in Radiological Protection Reference Values, 1st ed., ICRP, Ottawa, Canada, 2002.

Retrieved from:

http://radon-and-life.narod.ru/pub/ICRP 89.pdf Retrieved on: Jan. 16, 2017

5. Installation and Users Manual - TudorScan OCV MB Telecom Ltd., Ilfov, Romania, 2017.

6. Technical Specification - TudorScan OCV, MB Telecom Ltd., Ilfov, Romania, 2017.

7. Radiation Safety for Personnel Security Screening Systems Using X-Ray or Gamma Radiation, ANSI N43.17, Jan. 1, 2009.

8. List of terrorist incidents in India, Wikipedia, the free encyclopedia.

Retrieved from: Retrieved from: https://en.wikipedia.org/wiki/List of terrorist incide nts in India

Retrieved on: Jan. 15, 2017

9. Terrorism Attacks in Turkey 1970-2016, DATAGRAVER

Retrieved from:

http://www.datagraver.com/case/terrorism-attacks-inturkey-1970-2016

Retrieved on: Jan. 17, 2017 